\title{
EVALUATION OF IN VITRO ANTI-INFLAMMATORY ACTIVITY AND HPTLC ANALYSIS OF PLANT PHYLLANTHUS FRATERNUS
}

\author{
BIRESH KUMAR SARKAR ${ }^{1}$, RAVI KUMAR ${ }^{1}$, REETA $^{1}$, S. C. VERMA ${ }^{2}$, SHASHI PAL ${ }^{3}$, RAMAIAH MADDI ${ }^{4}$, C. MURALI \\ KRISHNA ${ }^{5}$, RAVINDRA SINGH ${ }^{6}$
}

${ }_{1}^{1}$ Central Ayurveda Research Institute for Respiratory Disorders, (CCRAS, Ministry of AYUSH, Govt. of India) Moti Bagh Road, Patiala, Punjab, India, ${ }^{2}$ Principal Scientific Officer (Phyto/Org. Chemistry), PLIM Campus, Ghaziabad, U. P., India, ${ }^{3}$ Manav Bharati University, Solan, HP, India, ${ }^{4}$ Dept. of Pharmacognosy, Hindu College of Pharmacy, Amaravathi Road, Guntur 522002, A. P., India, ${ }^{5}$ Regional Ayurveda Research Institute for Skin disorders, (CCRAS, Ministry of AYUSH) Vijayawada, India, ${ }^{6}$ Central Council for Research in Ayurvedic Sciences (CCRAS), Ministry of AYUSH, Government of India, New Delhi 110058 Email: bireshsarkar@gmail.com

Received: 22 May 2017, Revised and Accepted: 22 Jul 2017

\section{ABSTRACT}

Objective: The present investigation evaluated in vitro anti-inflammatory activity of Phyllanthus fraternus. Inhibition of Cyclooxygenase and 5lipoxygenase was performed along with protein denaturation.

Methods: Alcoholic extract of plant was subjected to in vitro anti-inflammatory activity and HPTLC analysis.

Results: The results of anti-inflammatory activity showed significant inhibition in Cyclooxygenase and 5-lipoxygenase assay, extract also showed more than $70 \%$ inhibition in protein denaturation method. HPTLC of plant materials was also performed; spots of alkaloids were recorded.

Conclusion: Different alkaloids were spotted in chromatographic analysis and study suggested that anti-inflammatory activity of Phyllanthus fraternus may be due to the presence of alkaloids.

Keywords: Anti-inflammatory, Phyllanthus Fraternus, HPTLC, Cyclooxygenase, Lipoxygenase

(C) 2017 The Authors. Published by Innovare Academic Sciences Pvt Ltd. This is an open access article under the CC BY license (http://creativecommons.org/licenses/by/4.0/] DOI: http://dx.doi.org/10.22159/ijcpr.2017v9i5.22328

\section{INTRODUCTION}

Inflammation is a process which associated with pain and various biochemical responses such as; protein denaturation, an increase of vascular permeability and membrane alteration. When protein loses its structural integrity due to the external stress then this is called protein denaturation; which involves reduced biological functioning of the protein. Protein denaturation is considered as an important cause of inflammation. The cascade of an inflammatory process initiated from arachidonic acid which forms prostaglandins (PGs) and thromboxane via Cyclooxygenase (COX) pathway and hydroperoxy-eicosatetraenoic acids (HPETE's) and leukotrienes (LT's) via 5-lipoxygenase pathway; these all mediators leads inflammatory events. The process of 5-LOX and COX inhibition adopted as an anti-inflammatory concept since inhibition of 5-LOX and COX also inhibit production of inflammatory mediators such as; LTs and PGs and thus offer anti-inflammatory responses. Therefore the agent which possesses the ability to inhibit 5-LOX and COX provide anti-inflammatory and analgesic effects with reduced GI side-effects [1-4].

Plants and plant products act as natural sources for various bioactive compounds which possess diversified biological activities such as; anti-hepatotoxic, anti-dysentric, anti-inflammatory, antispasmodic, anti-viral, anti-diabetes, wound healing and anti-cancer properties. The primary and secondary metabolites of plants are considered responsible for these properties. The biologically active constituent of plant material may reside in any part of a plant like; leaf, stem, root, seed and in the whole plant. Various researchers investigated and isolated different phytoconstituents as antiinflammatory agents, the some plant alkaloids known to have antiinflammatory properties along with other biological activities [2-5]. This article evaluated anti-inflammatory activity along with chromatographic estimations of alkaloids of Phyllanthus fraternus.

Phyllanthus fraternus Webster known as Bhoi amli is an important medicinal plant, belongs from family Euphorbiaceae, chemically it possess constituents such as; Phyllanthin, Hypophyllanthin, Phyllnirurin, Phyllanthenol, Phyllanthol, Rhamnopyrenoside, Phyllanthenone, Lintetralin, Astragalin, Cymene, Niranthin, Niruriside, Nirtetralin, Phyllochrysine, 4-Methoxy-Nirsecurinine, Niruretin, Limonene and Nirurin (Alkaloids). It contains Steroids; $\beta$ Sitosterol and Cholesterol, Flavonoids; Quercetin, Quercetol and 3, 4, 5-Trimethoxy flavanone, Saponins; triacontanol and triacontanol. The plant also contains compounds like; Carilagin, Estradiol, Ellagic acid, Rutin, Rutinoside, Gernanine and Methyl salicylate.

The Phyllanthus fraternus also known to have diversified biological actions such as; carminative, diuretic and astringent properties. It possesses anti-dysentric, anti-inflammatory, antispasmodic, antiseptic and anti-viral activities. The plant is also used in vertilago, malaria, diabetes, jaundice, indigestion, anemia, gout, cough, dermatosis, urinary disease and vaginitis [5-8].

\section{MATERIALS AND METHODS}

Plant materials were collected and subjected for extraction. All the reagents and solvents used were of analytical grade.

\section{Extraction}

Powdered plant materials were extracted with methanol then cooled and filtered through filter paper (Whatman No. 1) followed by centrifugation for $10 \mathrm{~min}$, further diluted in ratio of 1:15 with the same solvent, the procedure repeated for several time to obtained concentrated extract and final extract was used for further experiments except for HPTLC analysis [9].

\section{In vitro anti-inflammatory activity [10-16]}

\section{Inhibition of protein denaturation}

The reaction mixture consisted of $0.45 \mathrm{ml}$ of bovine serum albumin (5\% aqueous solution) and $0.05 \mathrm{ml}$ of plant extracts in various concentrations; $\mathrm{pH}$ was adjusted at 6.3 using $1 \mathrm{~N}$ hydrochloric acid. Heated at $57{ }^{\circ} \mathrm{C}$ for $3 \mathrm{~min}$ after incubating at $37^{\circ} \mathrm{C}$ for $20 \mathrm{~min}$., that 
after $2.5 \mathrm{ml}$ of phosphate buffer solution was added into each test tube. Turbidity was measured spectrophotometrically at $600 \mathrm{~nm}$. Distilled water $(0.05 \mathrm{ml})$ was used instead of extracts as control tests; while product control tests lacked bovine serum albumin.

The percentage inhibition of protein denaturation was calculated as follows:

$$
\text { Percentage inhibition }=\frac{100-(\text { O.D. of test }- \text { O.D. of product control })}{\text { O.D. of Control }} \times 100
$$

\section{Assay of cyclooxygenase and 5-lipoxygenase}

\section{Lymphocyte culture preparation}

Human peripheral lymphocytes were cultured in RPMI 1640 media, supplemented with fetal bovine serum, Penicillin and Streptomycin were used as antibiotics. Phytohaemagglutinin was used as the stimulant for cell proliferation, $0.2 \mu \mathrm{m}$ sized cellulose acetate filter was used to filter culture in aseptic conditions. Fresh plasma was added to the culture in $1 \times 106$ cells/ml concentrations; culture was incubated for $72 \mathrm{~h}$. The culture was activated by adding $1 \mu \mathrm{l}$ lipopolysaccharide, extracts were added at $24 \mathrm{hr}$ of incubation. Ibuprofen was added as standard. After incubation, the cells were pelleted by centrifugation. The isolation was done by spinning at $6000 \mathrm{rpm}$ for $10 \mathrm{~min}, 50 \mu \mathrm{l}$ of cell lysis buffer was added after discarding supernatant and the anti-inflammatory assay was done in pellet suspended in a small amount of supernatant.

\section{Assay of cyclooxygenase}

Tris-HCl buffer, glutathione, haemoglobin and enzyme was used as assay mixture. The arachidonic acid was added initially and after 20 min. incubated at $37{ }^{\circ} \mathrm{C}$ adding $0.2 \mathrm{ml}$ of $10 \%$ trichloroacetic acid in $1 \mathrm{~N} \mathrm{HCl}$ and $0.2 \mathrm{ml}$ of thiobarbituric acid, that after contents were heated in boiling water bath for $20 \mathrm{~min}$, cooled and centrifuged at $1000 \mathrm{rpm}$ for $3 \mathrm{~min}$. The supernatant was measured at $632 \mathrm{~nm}$ for COX activity.

\section{Assay of 5-lipoxygenase}

Linoleic acid along with tween 20 was dissolved in oxygen free water avoiding air bubbles, $0.5 \mathrm{~N}$ sodium hydroxide was added sufficiently to produce a clear solution and then the volume was made up to $25 \mathrm{ml}$ using oxygen free water. This was flushed with nitrogen gas before closing and kept frozen until needed after dividing into $0.5 \mathrm{ml}$ portions. The assay mixture consisted of $2.75 \mathrm{ml}$ Tris buffer of $\mathrm{pH} 7.4,0.2 \mathrm{ml}$ of sodium linoleate and $50 \mathrm{mcl}$ of the enzyme. Optical density was measured at $234 \mathrm{~nm}$.

\section{High-performance thin layer chromatography (HPTLC) [17-20]}

\section{Isolation of alkaloids}

Dried powdered sample was suspended in methanol, stirred and filtered. The sample was further washed with methanol and filtrate was collected. After repeating process alcoholic filtrates were mixed together and concentrated. The dried content was dissolved in a mixture of ethyl acetate and $1 \mathrm{~N} \mathrm{HCl}$ in equal amount. The acidic aqueous portion was removed while remaining fraction of ethyl acetate was repeatedly washed with $1 \mathrm{~N} \mathrm{HCl}$. The acidic aqueous fraction was neutralized with sodium bicarbonate and $\mathrm{pH}$ was adjusted at 10 using $\mathrm{NaOH}$ solution and then partitioned with ethyl acetate. The ethyl acetate fractions were evaporated to dryness and dry residue was triturated with dichloromethane and filtered. The filtrate was used for indole alkaloids.

\section{Chromatographic condition}

HPTLC precoated plate, silica gel $60 \mathrm{~F} 254,10 \times 10 \mathrm{~cm}^{2}$, thickness $250 \mu \mathrm{m}$ were used. Samples were injected using Linomat injector. Methanol: Ethyl acetate (2:8) was used as mobile phase. 1\% Cerric ammonium sulphate was used as spraying reagent. Relative humidity and temperature were $52 \%$ and $24{ }^{\circ} \mathrm{C}$ respectively. The 80 $\mathrm{mm}$ migration distance was allowed for $30 \mathrm{~min}$. Densitometric scanning was performed using UV detector at $254 \mathrm{~nm}$. Ascending separation technique was used in twin-trough glass chamber $(10 \mathrm{X}$
$10 \mathrm{~cm}^{2}$ ) which was used as development chamber; saturation of chamber was done prior to development.

\section{RESULTS AND DISCUSSION}

\section{In vitro anti-inflammatory activity}

The extract of Phyllanthus fraternus was analyzed for anti inflammatory activity using various in vitro models. The results of the study proved that extract possesses ability to inhibit denaturation of proteins and thus may offer significant relief in inflammation. The inhibition of heat induced albumin denaturation by sample extract presented in table 1 . The evaluation of cyclooxygenase and 5-lipoxygenase inhibitory activity of plant extract was also performed. The results are tabulated in table 2, the results of COX and 5LOX assay also compared and presented in fig. 1, as result indicated more COX inhibition was observed as compared to 5LOX inhibition. The results of the study suggested that the plant extract may reduce productions of inflammatory mediators such as; prostaglandins and leukotriene's since it significantly inhibits cyclooxygenase and 5-lipoxygenase respectively; this anti-inflammatory activity of plant extract may be due to the presence of alkaloids and polyphenols.

It has been reported that the inhibition of prostaglandins and leukotriene leads anti-inflammatory response. The inhibition of COX may cause gastric side effects due to the possible mucosal damage; however inhibition of 5-LOX decreases the production of a compound which may cause gastric damage; thus inhibition of COX along with 5LOX recommended to achieve maximum anti-inflammatory activity with gastric safety. This dual inhibition prevents the production of prostaglandins and leukotrienes resulting inhibition of migration and activation of inflammatory cells at the sites of inflammation. The inhibition of this inflammatory cascade also reduces tissue damage or necrosis. The results of study suggested that Phyllanthus fraternus plant extract may be used as anti-inflammatory agent with gastric safety.

Table 1: Results of protein denaturation assay

\begin{tabular}{lll}
\hline S. No. & Concentration $(\mathbf{m c g} / \mathbf{m l})$ & \% inhibition \\
\hline 1 & 100 & 32.21 \\
2 & 150 & 45.54 \\
3 & 200 & 57.55 \\
4 & 250 & 66.55 \\
5 & 300 & 72.23 \\
\hline
\end{tabular}

Table 2: Results of cyclooxygenase and 5-lipoxygenase assay

\begin{tabular}{llll}
\hline S. No. & Concentration $(\mathbf{m c g} / \mathbf{m l})$ & \multicolumn{2}{c}{ \% inhibition } \\
\cline { 3 - 4 } & & COX assay & 5-LOX assay \\
\hline 1 & 50 & 33.11 & 22.31 \\
2 & 100 & 36.14 & 35.34 \\
3 & 150 & 49.12 & 46.53 \\
4 & 200 & 60.22 & 59.15 \\
5 & 250 & 73.43 & 70.21 \\
\hline
\end{tabular}

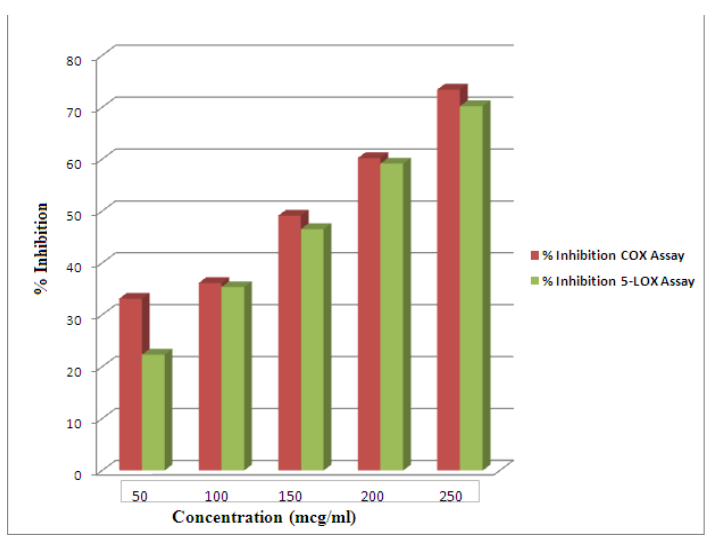

Fig. 1: Comparison of COX and 5-LOX assay 
HPTLC analysis was also performed to identify alkaloid of plant extract of P. fraternus. HPTLC results identified peaks of alkaloids as mentioned in fig. 2. Densitometric chromatograms of alkaloids were observed with different peak area which proved that various alkaloids found in different concentrations. The correlation coefficient suggested a linear relationship. The presence of alkaloids in $P$. fraternus confirmed by HPTLC analysis and these compounds may be considered responsible for the investigated anti-inflammatory activity.

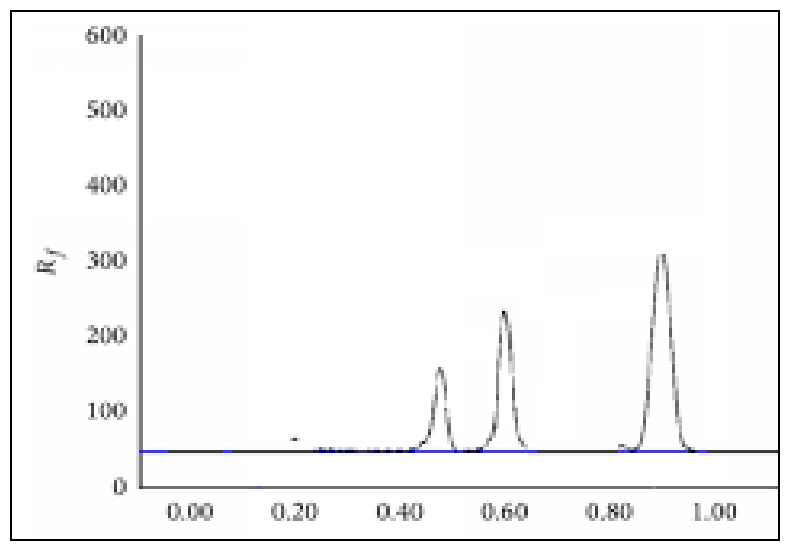

Fig. 2: HPTLC chromatograms of alkaloids present in Phyllanthus fraternus

\section{CONCLUSION}

Alcoholic extract of plant Phyllanthus fraternus was subjected to in vitro anti-inflammatory activity and HPTLC analysis. The results of anti-inflammatory activity observed significant inhibition of Cyclooxygenase and 5-lipoxygenase, the present investigation concluded that Phyllanthus fraternus may be used as potent antiinflammatory agents with higher gastric safety profile. The results of protein denaturation assay also proved anti-inflammatory profile of Phyllanthus fraternus. HPTLC analysis confirmed presence of alkaloids in plant extract and these alkaloids may be responsible for the anti-inflammatory activity of Phyllanthus fraternus.

\section{CONFLICT OF INTERESTS}

\section{Declare none}

\section{REFERENCES}

1. Leelaprakash G, Mohan Dass S. In vitro anti-inflammatory activity of methanol extract of Enicostemma axillare. Int J Drug Dev Res 2010;3:189-96.

2. Uma SA, Bharti 0 . In vitro 5-Lipoxygenase inhibition of polyphenolic antioxidants from undomesticated plants of South Africa. J Med Plants Res 2008;2:207-12.

3. Pelletier. In: Molecular biology and biotechnology. Nag TN. Alka Publications, Ajmer, India; 1999.

4. Vasil IK. Cell culture and somatic cell genetics of plants. Vol. I. Laboratory procedures and their applications, Academic Press, Inc. Harcourt Brace Jovanovich Publishers; 1984.
5. Ahmad B, Alam T. Components from whole plant of Phyllanthus amarus L., Indian J Chem 2003;42B:1786-90.

6. Filho VC, Santos ARS, Calixto JB, Monache FD, Miguel OG, Yunes RA. Triterpenes from Phyllanthus sellowianus roots. Planta Med 1998;68:194.

7. Miguel OG, Calixto JB, Santos ARS, Messana I, Ferrari F, Filho $\mathrm{VC}$, et al. Chemical and preliminary analgesic evaluation of geraniin and furosin isolated from Phyllanthus sellowianus. Planta Med 1996;62:146-9.

8. Kurup PNV, Ramadas VNK, Johri, Shri Prajapati. Handbook of medicinal plants, CCRAS Publishers, New Delhi; 1979.

9. Khandelwal KR. Practical pharmacognosy: techniques and experiments. $4^{\text {th }}$ ed. Nirali Prakashan, India; 1998.

10. Vallabh D, Varsha MJ, Kadam VJ. In vitro anti-arthritic activity of Abutilon indicum (Linn.) sweet. J Pharm Res 2009;49:644-5.

11. Viji V, Helen A. Inhibition of lipoxygenases and cyclooxygenase2 enzymes by extracts isolated from Bacopa monniera (L.) Wettst. J Ethnopharmacol 2008;118:305-11.

12. Kumar A, Bendre A. A textbook of practical botany. Vol. I, II. Rastogi Publications, Meerut, India; 1986.

13. Udegbunam RI, Obinna KN, Udegbunam SO, Chinaka ON, Gregory EO. Evaluation of anti-inflammatory activities of root extracts of Stephania dinklagei (Engl.) Diels. Afr J Pharm Pharmacol 2010;6:834-9.

14. Confortia F, Sosab S, Marrellia M, Menichinia F, Giancarlo AS Dimitar $\mathrm{U}$, et al. In vivo anti-inflammatory and in vitro antioxidant activities of mediterranean dietary plants. J Ethnopharmacol 2008;116:144-51.

15. Guzik TJ, Korbut R, Adamek-Guzik T. Nitric oxide and superoxide in inflammation and immune regulation. J Physiol Pharmacol 2003;54:469-87.

16. Martel-Pelletier J, Lajeunesse D, Reboul P, Pelletier JP Therapeutic role of dual inhibitors of 5-LOX and COX, selective and non-selective non-steroidal anti-inflammatory drugs. Ann Rheumatic Diseases ECLAR J 2003;62:501-9.

17. Constabel F, Rambold S, Chatson KB, Kurz WGW, Kutney JP. Alkaloid production in Catharanthus roseus (L.) G. Don. VI Variation in alkaloid spectra of cell lines derived from one single leaf. Plant Cell Report 1981;1:3-5.

18. Sethi PD. HPTLC (High-Performance Thin Layer Chromatography) Quantitative analysis of pharmaceutical formulations, CBS publishers and Distributors, New Delhi; 1996.

19. Shah SA, Ravishankara MN, Nirmal A, Shishoo CJ, Rathod IS, Suhagia BN. Estimation of individual sennosides in plant materials and marketed formulations by HPTLC method. J Pharm Pharmacol 2000;52:445-9.

20. Ravishankara MN, Shrivastava N, Padh H, Rajani M. HPTLC method for the estimation of alkaloids of Cinchona officinalis stem bark and its marketed formulations. Planta Med 2001;67:294-6.

\section{How to cite this article}

- $\quad$ Biresh Kumar Sarkar, Ravi Kumar, Reeta, SC Verma, Shashi Pal, Ramaiah Maddi, C Murali Krishna, Ravindra Singh. Evaluation of in vitro anti-inflammatory activity and HPTLC analysis of plant Phyllanthus fraternus. Int J Curr Pharm Res 2017;9(5):198-200. 